\title{
Systematic review and meta-analysis of $\mathrm{T} 1$ glottic cancer outcomes comparing $\mathrm{CO}_{2}$ transoral laser microsurgery and radiotherapy
}

Michael F. Vaculik', Colin A. MacKay², S. Mark Taylor², Johnathan R. B. Trites², Robert D. Hart² and Matthew H. Rigby ${ }^{2 *}$

\begin{abstract}
Background: The objective of this study is to compare the oncologic outcomes of $\mathrm{CO}_{2}$ transoral laser microsurgery (TLM) and radiotherapy (RT) for treatment of T1 glottic carcinoma.

Methods: A literature search was conducted in the following databases: Medline/PubMed, Web of Science, EMBASE, and the Cochrane Library. Search results were screened, and publications comparing oncologic outcomes of T1NOMO glottic carcinoma treated with TLM or RT were included. Data was extracted independently by two authors, and publication quality was graded according to the Oxford Centre for Evidence-based Medicine. Metaanalysis was performed for overall survival, disease specific survival, laryngeal preservation, and local control.

Results: Sixteen studies were included in the meta-analysis, the majority being retrospective cohort studies with two prospective cohort studies. Included studies were rated as either Level II or III evidence. Meta-analysis favoured treatment with TLM for T1 glottic carcinoma patients for the following outcomes: overall survival (odds ratio [OR], $1.52 ; 95 \%$ confidence interval $[\mathrm{Cl}], 1.07-2.14 ; P=0.02)$, disease specific survival $(\mathrm{OR}, 2.70 ; \mathrm{Cl}, 1.32-5.54 ; P=0.007)$, and laryngeal preservation $(\mathrm{OR}, 6.31 ; \mathrm{Cl}, 3.77-10.56 ; P<0.00001)$. There was no difference in local control between TLM and RT in $\mathrm{T} 1$ glottic cancer (OR, 1.19; $\mathrm{Cl}, 0.79-1.81 ; P=0.40)$.

Discussion: Our study provides a current and thorough comparison of TLM and RT outcomes in T1 glottic carcinoma. Limitations of our study include lack of randomized control trials, and non-randomized allocation of patients to treatment groups. Our meta-analysis suggests that TLM is the superior modality in terms of overall survival, disease specific survival, and laryngeal preservation. Future prospective randomized controlled studies are required for confirming these findings and developing appropriate clinical practice guidelines.
\end{abstract}

Level of evidence: 2A; as per the Centre of Evidence Based Medicine.

Keywords: Early glottic cancer, Transoral laser microsurgery, Radiotherapy, Survival

\footnotetext{
* Correspondence: mhrigby@dal.ca

2Dalhousie Division of Otolaryngology - Head and Neck Surgery, Dalhousie University, Suite 3044, Dickson Bldg. 5820 University Avenue, Halifax, NS B3H 1V9, Canada

Full list of author information is available at the end of the article
}

(c) The Author(s). 2019 Open Access This article is distributed under the terms of the Creative Commons Attribution 4.0 International License (http://creativecommons.org/licenses/by/4.0/), which permits unrestricted use, distribution, and reproduction in any medium, provided you give appropriate credit to the original author(s) and the source, provide a link to the Creative Commons license, and indicate if changes were made. The Creative Commons Public Domain Dedication waiver (http://creativecommons.org/publicdomain/zero/1.0/) applies to the data made available in this article, unless otherwise stated. 


\section{Introduction}

Cancer of the larynx is the most common head and neck malignancy, with an estimated 1150 new cases in Canada in 2017 [1]. In recent years, incidence rates in both men and women have declined, which reflects a reduction in the use of proven risk factors including cigarettes and alcohol. Nevertheless, about 440 Canadians died from laryngeal cancer in 2017 [1]. About two-thirds of laryngeal cancers arise in the glottic area, the majority of which are diagnosed early, partly due to larynx anatomy, specifically its encasement in cartilage with sparse lymphatics, and partly due to early onset of symptoms including hoarseness. Early diagnosis provides an important opportunity for organ preservation and cure. As a result, the selection of optimal management is crucial in maximizing oncologic and functional outcomes.

In the past, laryngeal cancers were traditionally treated with radiotherapy (RT) or open partial laryngeal surgery. Transoral laser microsurgery (TLM) for glottic cancer was first described in 1972 by Strong and Jako [2], and later popularized in 1988 by Steiner [3]. Currently, TLM and RT are both acceptable treatment modalities for early glottic cancer, with open surgery now falling out of favour [4]. It is evident that these therapies may differ in side-effect profile and cost in the short term, however, there remains debate on which results in better functional and oncologic outcomes [5-7]. At present, there is a paucity of high quality prospective evidence in academic literature directly comparing TLM and RT in early glottic cancer. According to a recent Cochrane review, there is just one randomized-control trial (RCT) published in 1990 that compares TLM, open surgery, and radiotherapy in 234 patients with early glottic cancer [8]. This study, however, does not offer sufficient evidence to guide clinical decision making. As a result, surgeons must rely on the critical appraisal of non-randomized studies with variable patient populations, cancer staging, and outcomes. Adding to the complexity of therapy selection is patient preference, clinical characteristic, and availability of either modality across institutions. Predictably, current opinions of optimal therapy differ across disciplines and countries $[9,10]$.

To our knowledge, an international standard guiding therapeutic selection in early glottic carcinoma does not exist. In order to improve clinical decision making, we systematically reviewed the literature for studies directly comparing TLM and RT in T1 glottic carcinoma and performed a meta-analysis of critical oncologic outcomes including overall survival, disease-specific survival, laryngeal preservation, and local control. Although previous reviews have investigated this question, our systematic review provides an updated analysis. For instance, Mo et al. in 2017 [6] includes eleven studies published before January 2012. In comparison, our systematic review includes sixteen studies, five of which [11-15] published after January 2012. We also excluded single arm studies from our review, whereas Higgins et al. [16] assessed overall survival by exclusively comparing single arm TLM and RT studies. As a result, our analysis provides a current and rigorous review of this question.

\section{Methods}

\section{Literature search strategy}

Literature searches were conducted independently by authors MFV and CAM in the following electronic databases: Medline/PubMed, Web of Science, EMBASE, and the Cochrane Library. These databases were selected to provide a broad search of high quality medical research and allowed for a thorough scope of the available literature. Searches were designed to combine disease specific terms (neoplasm, cancer, malignan*, carcinoma*, tumour*, tumor*, SCC), site specific terms (larynx, laryn*, glott*, throat, 'voice box', 'vocal cord'), and treatment specific terms for TLM (surgery, 'larynx surgery', 'transoral laser microsurgery', 'trans oral laser microsurgery', 'endoscopic surgery', microsurgery, 'CO2 laser', 'carbon dioxide laser'), and RT (radiotherapy, radiotherap", irradiat", radiat", 'rt', radiation). Searches in separate databases were similarly constructed, using the Boolean operator 'AND' to combine disease, site, and treatment specific term categories. All searches were conducted between March and May 2017.

\section{Inclusion and exclusion criteria}

Search results for each database were imported in EndNote X8.2 software by Clarivate Analytics. According to currently accepted practises, duplicate results between databases were retrieved using the "Find Duplicates" function in EndNote X8.2, and manually reviewed by author MFV prior to removal [17]. Titles and abstracts were then screened separately by authors MFV and CAM for the following inclusion criteria (1): patient with untreated T1N0M0 glottic carcinoma (2); comparative cohorts that received a primary treatment with either carbon dioxide TLM, or RT (3); analysis of one or more oncologic outcomes including overall survival, disease specific survival, local control rate, locoregional control rate, and laryngeal preservation rate. Studies were excluded if any of the following criteria were met (1): glottic cancer other than stage T1 (2); studies reporting only on functional results or voice quality (3); studies using KTP laser for TLM treatment; and (4) single-arm studies reporting on one of the two therapy methods, or (5); studies with incomplete data. Selected studies had their bibliographies cross-referenced for any unidentified publications. Database searches also retrieved systematic and other literature reviews, whose bibliographies were independently screened by both MFV and CAM for 
additional studies meeting inclusion criteria. For differences in inclusion between screening authors, a discussion was held and consensus reached on inclusion or exclusion. Only abstracts in English were reviewed. Some non-English studies were retrieved in the search however they did not meet the stated the inclusion criteria. Finally, when data were felt to have been duplicated by authors in more than one manuscript, the most recent study was included for the current review.

\section{Data extraction}

Full texts of eligible studies according to the above inclusion criteria were retrieved and carefully searched independently by authors MFV and CAM. For each text, study characteristic data was extracted and reported in
Table 1, including year of publication, location of study, study design, study period for data collection, stages of glottic cancer included, staging system if reported, study comparison arms, follow-up time for which data is reported, mean age of participants and age range if reported, and the quality assessment score. Sample size and oncologic outcome data was extracted and reported in Table 2. Oncologic outcomes, including overall survival, disease free survival, local control, and laryngeal preservation are reported as events to facilitate metaanalysis. Percentages displayed in Table 2 were calculated as events over sample size, and are not the reported Kaplan Meier data. Not all eligible studies reported data on all of the oncologic outcome measures. Additionally, data for oncologic outcomes was not

Table 1 Characteristics of the included studies

\begin{tabular}{|c|c|c|c|c|c|c|c|c|c|c|c|c|c|}
\hline Study & Year & Country & Design & $\begin{array}{l}\text { Study } \\
\text { Period }\end{array}$ & $\begin{array}{l}\text { Cancer } \\
\text { Staging }\end{array}$ & Arms & Stages & $\begin{array}{l}\text { Sample } \\
\text { Size }\end{array}$ & $\begin{array}{l}\text { Sex } \\
(M: F)\end{array}$ & $\begin{array}{l}\text { Mean } \\
\text { Age } \\
\text { (range) }\end{array}$ & $\begin{array}{l}\text { Selection } \\
\text { Bias }\end{array}$ & $\begin{array}{l}\text { ELS } \\
\text { Type }\end{array}$ & $\begin{array}{l}\text { Quality } \\
\text { Score }\end{array}$ \\
\hline $\begin{array}{l}\text { Low et al. } \\
\text { [11] }\end{array}$ & 2017 & Canada & retro & $2003-2013$ & NR & TLM, RT & T1a & 105 & $86: 19$ & 68 & NR & $N R$ & $\begin{array}{l}\text { Level } \\
\text { III }\end{array}$ \\
\hline $\begin{array}{l}\text { Alkan et al. } \\
{[12]}\end{array}$ & 2017 & Israel & retro & 2006-2013 & NR & TLM, RT & $\begin{array}{l}\text { T1a } \\
\text { T1b }\end{array}$ & $\begin{array}{l}23 \\
31\end{array}$ & $46: 8$ & $\begin{array}{l}68 \\
(36-95)\end{array}$ & $\begin{array}{l}\text { AC, Age, } \\
\text { Tumor }\end{array}$ & $\mathrm{IV} / \mathrm{V}$ & $\begin{array}{l}\text { Level } \\
\text { III }\end{array}$ \\
\hline $\begin{array}{l}\text { Taylor et al. } \\
\text { [13] }\end{array}$ & 2013 & Canada & pro & 2002-2010 & NR & TLM, RT & $\mathrm{T} 1 \mathrm{~b}$ & 63 & $57: 6$ & 67 & NR & NR & $\begin{array}{l}\text { Level } \\
\text { ॥ }\end{array}$ \\
\hline $\begin{array}{l}\text { Remmelts } \\
\text { et al. [14] }\end{array}$ & 2013 & Netherlands & retro & $2000-2008$ & $\begin{array}{l}200 ; 2 \\
\text { UICC }\end{array}$ & TLM, RT & $\begin{array}{l}\text { Tis } \\
\text { T1a } \\
\text { T1b } \\
\text { T2 }\end{array}$ & $\begin{array}{l}26 \\
103 \\
42 \\
77\end{array}$ & $88: 12$ & $\begin{array}{l}65 \\
(39-89)\end{array}$ & NR & $N R$ & $\begin{array}{l}\text { Level } \\
\text { III }\end{array}$ \\
\hline $\begin{array}{l}\text { Kerr et al. } \\
{[15]}\end{array}$ & 2012 & Canada & retro & $2002-2010$ & NR & TLM, RT & $\begin{array}{l}\text { T1a } \\
\text { T1b } \\
\text { T2 }\end{array}$ & $\begin{array}{l}146 \\
41 \\
46\end{array}$ & $205: 29$ & 67 & $N R$ & $N R$ & $\begin{array}{l}\text { Level } \\
\text { III }\end{array}$ \\
\hline $\begin{array}{l}\text { Kujath et al. } \\
{[20]}\end{array}$ & 2011 & Canada & retro & 2000-2009 & NR & TLM, RT & $\begin{array}{l}\mathrm{T} 1 \\
\mathrm{~T} 2\end{array}$ & $\begin{array}{l}64 \\
15\end{array}$ & $69: 10$ & $N R$ & $\begin{array}{l}\text { Time } \\
\text { Period }\end{array}$ & $N R$ & $\begin{array}{l}\text { Level } \\
\text { III }\end{array}$ \\
\hline $\begin{array}{l}\text { Mahler et al. } \\
\text { [25] }\end{array}$ & 2010 & Norway & pro & 1986-2005 & $\begin{array}{l}2002 \\
\text { UICC }\end{array}$ & TLM, RT & T1a & 351 & $318: 33$ & $\begin{array}{l}66 \\
(31-90)\end{array}$ & $\begin{array}{l}\text { Time } \\
\text { period }\end{array}$ & $N R$ & $\begin{array}{l}\text { Level } \\
\text { ॥ }\end{array}$ \\
\hline $\begin{array}{l}\text { Schrijvers } \\
\text { et al. [26] }\end{array}$ & 2009 & Netherlands & retro & 1990-2004 & $\begin{array}{l}2002 \\
\text { AJCC }\end{array}$ & TLM, RT & T1a & 100 & $88: 12$ & $\begin{array}{l}66 \\
(38-83)\end{array}$ & $\begin{array}{l}\text { Time } \\
\text { period }\end{array}$ & | / || & $\begin{array}{l}\text { Level } \\
\text { III }\end{array}$ \\
\hline $\begin{array}{l}\text { Thurnher } \\
\text { et al. [28] }\end{array}$ & 2008 & Austria & retro & 1948-1997 & $\begin{array}{l}2002 \\
\text { UICC }\end{array}$ & $\begin{array}{l}\text { TLM, RT, } \\
\text { PL }\end{array}$ & T1a & 337 & $309: 28$ & $\begin{array}{l}63 \\
(28-90)\end{array}$ & NR & NR & $\begin{array}{l}\text { Level } \\
\text { III }\end{array}$ \\
\hline $\begin{array}{l}\text { Sjögren } \\
\text { et al. [23] }\end{array}$ & 2008 & Netherlands & retro & 1996-2007 & NR & TLM, RT & T1a & 181 & $165: 15$ & $\begin{array}{l}70 \\
(33-95)\end{array}$ & $A C$ & | / || & $\begin{array}{l}\text { Level } \\
\text { III }\end{array}$ \\
\hline $\begin{array}{l}\text { Goor } \\
\text { et al. [22] }\end{array}$ & 2007 & Netherlands & retro & 1995-1999 & NR & TLM, RT & T1a & 89 & $85: 4$ & $\begin{array}{l}65 \\
(42-83)\end{array}$ & $\begin{array}{l}\text { Tumor } \\
\text { (Depth) }\end{array}$ & $\|$ & $\begin{array}{l}\text { Level } \\
\text { III }\end{array}$ \\
\hline $\begin{array}{l}\text { Krengli } \\
\text { et al. [18] }\end{array}$ & 2004 & Italy & retro & 1990-2001 & NR & TLM, RT & T1a & 57 & $55: 2$ & $\begin{array}{l}68 \\
(55-81)\end{array}$ & NR & III / IV & $\begin{array}{l}\text { Level } \\
\text { III }\end{array}$ \\
\hline $\begin{array}{l}\text { Stoeckli et al. } \\
\text { [19] }\end{array}$ & 2003 & Switzerland & retro & 1990-1998 & $\begin{array}{l}1997 \\
\text { UICC }\end{array}$ & TLM, RT & $\begin{array}{l}\mathrm{T} 1 \\
\mathrm{~T} 2\end{array}$ & $\begin{array}{l}101 \\
39\end{array}$ & $132: 8$ & $\begin{array}{l}63 \\
(41-88)\end{array}$ & $\begin{array}{l}\text { Stage, } \\
\text { Tumor }\end{array}$ & NR & $\begin{array}{l}\text { Level } \\
\text { III }\end{array}$ \\
\hline $\begin{array}{l}\text { Brandenburg } \\
{[21]}\end{array}$ & 2001 & USA & retro & 1989-1999 & $N R$ & TLM, RT & $\begin{array}{l}\text { T1a } \\
\text { T1b }\end{array}$ & $\begin{array}{l}70 \\
4\end{array}$ & $65: 9$ & $\begin{array}{l}64 \\
(33-88)\end{array}$ & $A C$ & NR & $\begin{array}{l}\text { Level } \\
\text { III }\end{array}$ \\
\hline $\begin{array}{l}\text { Rosier et al. } \\
{[24]}\end{array}$ & 1998 & Belgium & retro & 1979-1995 & $\begin{array}{l}1987 \\
\text { UICC }\end{array}$ & $\begin{array}{l}\text { TLM, RT, } \\
\text { PL }\end{array}$ & $\begin{array}{l}\text { T1a } \\
\text { T1b }\end{array}$ & $\begin{array}{l}81 \\
25\end{array}$ & $93: 13$ & $\begin{array}{l}64 \\
(43-88)\end{array}$ & $\begin{array}{l}\text { Age, AC, } \\
\text { Stage }\end{array}$ & NR & $\begin{array}{l}\text { Level } \\
\text { III }\end{array}$ \\
\hline $\begin{array}{l}\text { Epstein et al. } \\
{[27]}\end{array}$ & 1990 & USA & retro & 1975-1987 & $\begin{array}{l}1988 \\
\text { AJCC }\end{array}$ & TLM, RT & T1a & 77 & $71: 6$ & 63 & NR & NR & $\begin{array}{l}\text { Level } \\
\text { III }\end{array}$ \\
\hline
\end{tabular}


Table 2 Survival outcomes of the included studies

\begin{tabular}{|c|c|c|c|c|c|c|c|c|c|c|c|c|}
\hline \multirow[t]{2}{*}{ Study } & \multirow{2}{*}{$\begin{array}{l}\text { Stages } \\
\text { Included } \\
\text { in } \\
\text { Analysis }\end{array}$} & \multirow{2}{*}{$\begin{array}{l}\text { Mean } \\
\text { Follow- } \\
\text { Up } \\
\text { Time }\end{array}$} & \multicolumn{2}{|c|}{ Sample Size } & \multicolumn{2}{|l|}{ OS \% (n) } & \multicolumn{2}{|l|}{ DSS \% (n) } & \multicolumn{2}{|l|}{ LP \% (n) } & \multicolumn{2}{|l|}{ LC \% (n) } \\
\hline & & & TLM & RT & TLM & RT & TLM & RT & TLM & RT & TLM & RT \\
\hline _ow et al. [11] & T1a & $5 \mathrm{yrs}$ & 53 & 52 & $89(47)$ & $87(45)$ & $100(53)$ & $98(51)$ & $100(53)$ & $92(48)$ & $81(43)$ & $92(48)$ \\
\hline Alkan et al. [12] & $\mathrm{T} 1 \mathrm{a}, \mathrm{T} 1 \mathrm{~b}$ & $5 \mathrm{yrs}$ & 16 & 38 & $88(14)$ & $79(30)$ & $100(16)$ & $97(37)$ & $94(15)$ & $89(34)$ & $75(12)$ & $87(33)$ \\
\hline Taylor et al. [13] & $\mathrm{T1b}$ & $2 \mathrm{yrs}$ & 21 & 42 & $90(19)$ & $90(38)$ & $95(20)$ & $98(41)$ & $100(21)$ & $90(38)$ & $95(20)$ & $88(37)$ \\
\hline Remmelts et al. [14] & T1a & $5 \mathrm{yrs}$ & 50 & 54 & $90(45)$ & $81(44)$ & $100(50)$ & $98(53)$ & $100(50)$ & $96(52)$ & $90(45)$ & $94(51)$ \\
\hline Kerr et al. [15] & $\mathrm{T} 1 \mathrm{a}, \mathrm{T} 1 \mathrm{~b}$ & $2 \mathrm{yrs}$ & 125 & 62 & $94(118)$ & $95(59)$ & - & - & $100(125)$ & $92(57)$ & - & - \\
\hline Kujath et al. [20] & $\mathrm{T} 1$ & $3 \mathrm{yrs}$ & 51 & 46 & - & - & $100(51)$ & $100(46)$ & $100(51)$ & $91(42)$ & - & - \\
\hline Mahler et al. [25] & T1a & 3 yrs & 188 & 163 & $88(165)$ & $81(132)$ & $98(184)$ & $97(158)$ & $99(187)$ & $93(152)$ & $93(174)$ & $89(145)$ \\
\hline Schrijvers et al. [26] & T1a & $5 \mathrm{yrs}$ & 49 & 51 & $92(45)$ & $82(42)$ & $100(49)$ & $98(50)$ & $96(47)$ & $80(41)$ & $73(36)$ & $76(39)$ \\
\hline Thurnher et al. [28] & T1a & $5 \mathrm{yrs}$ & 81 & 108 & - & - & $100(81)$ & $91(98)$ & $100(81)$ & $84(91)$ & $90(73)$ & $69(75)$ \\
\hline Sjögren et al. [23] & T1a & $5 \mathrm{yrs}$ & 73 & 70 & $84(61)$ & $80(56)$ & $100(73)$ & $96(67)$ & $100(73)$ & $83(58)$ & $89(65)$ & $79(55)$ \\
\hline Goor et al. [22] & T1a & $2 \mathrm{yrs}$ & 54 & 31 & $100(54)$ & $100(31)$ & $100(54)$ & $100(31)$ & $100(54)$ & $97(30)$ & $94(51)$ & $90(28)$ \\
\hline Krengli et al. [18] & T1a & $5 \mathrm{yrs}$ & 122 & 80 & - & - & - & - & $96(117)$ & $91(73)$ & $96(117)$ & $91(73)$ \\
\hline Stoeckli et al. [19] & $\mathrm{T} 1$ & $5 \mathrm{yrs}$ & 56 & 45 & $91(51)$ & $89(40)$ & $96(54)$ & $96(43)$ & $96(54)$ & $82(37)$ & $88(49)$ & $82(37)$ \\
\hline Brandenburg [21] & $\mathrm{T} 1 \mathrm{a}, \mathrm{T} 1 \mathrm{~b}$ & $5 \mathrm{yrs}$ & 30 & 44 & - & - & $100(30)$ & $95(42)$ & $97(29)$ & $86(38)$ & $83(25)$ & $80(35)$ \\
\hline Rosier et al. [24] & $\mathrm{T} 1 \mathrm{a}, \mathrm{T} 1 \mathrm{~b}$ & $5 \mathrm{yrs}$ & 31 & 41 & - & - & - & - & - & - & $84(26)$ & $90(37)$ \\
\hline Epstein et al. [27] & T1a & $5 \mathrm{yrs}$ & 17 & 43 & - & - & - & - & $88(15)$ & $84(36)$ & $71(12)$ & $86(37)$ \\
\hline
\end{tabular}

Abbreviations: $R T$ radiotherapy, TLM transoral laser microsurgery, OS overall survival, DSS Disease Specific Survival, $L C$ local control, $L P$ laryngeal preservation, retro retrospective, pro prospective

included if only Kaplan Meier percentages were reported. For studies that reported on oncologic outcomes of stages other than T1, data was included if authors specified outcomes by stage. If differences in data extraction results occurred between authors, a consensus was reached through discussion with MHR.

\section{Retrieval results}

The search strategy retrieved 6502 unique studies, whose title, keywords, and abstract if necessary were reviewed independently by MFV and CAM. A total of $120 \mathrm{ab}-$ stracts were selected for analysis and were subsequently narrowed to 41 full-text articles (including 19 literature reviews). After comprehensive review, we found only 14 eligible studies from our search, with two additional studies retrieved from analyzing references of literature reviews. The final result was 16 eligible studies that met inclusion criteria [11-15, 18-28], and all reported baseline characteristics summarized in Table 1 . The steps that were followed to identify the appropriate studies are illustrated in Fig. 1.

\section{Study characteristics}

Of the sixteen eligible studies in our meta-analysis, ten were published within the last decade, and of these only six $[11-15,20]$ performed cancer treatment within this time period. Reporting of patient baseline characteristics varied greatly. The total number of patients in our meta- analysis pooled from all eligible studies was 1987, 1017 for the TLM arm and 970 for the RT arm, respectively. Five studies [11, 14, 20, 23, 26] had a balanced sample size in both treatment arms, whereas eleven studies $[12,13,15,18,19,21,22,24,25,27,28]$ had an unbalance sample size, of which just one study [25] reported an analysis for statistically significant differences in baseline patient characteristics between treatment arms. Eight studies $[11,15,18,19,22,23,25]$ had a larger sample size in the TLM arm compared to the RT arm. All studies, except for one [20], reported the mean age of participants, which was similar overall and ranged from 63 to 70 years.

In terms of glottic cancer staging and treatment, just seven studies reported use of a specific staging system, of which five studies [14, 19, 24, 25, 28] used the Union for International Cancer Control (UICC) staging system and two studies [26, 27] used the American Joint Committee on Cancer (AJCC) staging system. For TLM, just four studies reported laser parameters, including laser power used during surgery, with two studies [11, 25] reporting a laser power of $1-2 \mathrm{~W}$, one with $2-9 \mathrm{~W}$ laser power [14], and another with a large range of $0.5-55 \mathrm{~W}$ of power [24]. Additionally, just five studies [12, 18, 22, 23, 26] reported the type of cordectomy performed according to the European Laryngological Society [29]. Briefly, type of cordectomies are classified as follows: type I is a subepithelial cordectomy; type II is a subligamental cordectomy; type III is a transmuscular cordectomy; type IV is a total 


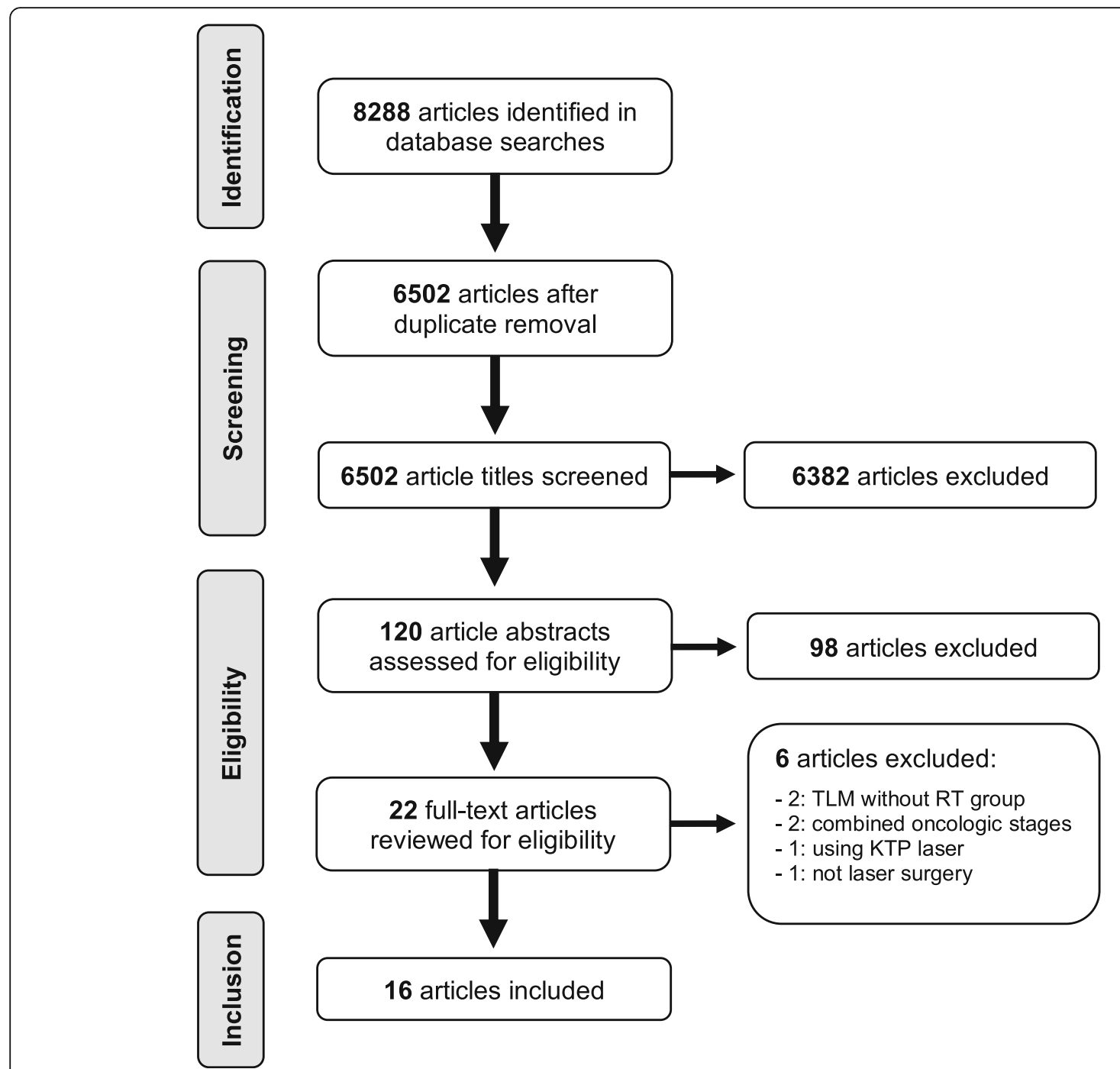

Fig. 1 PRISMA flow diagram of literature search and selection process

cordectomy; and type V is an extended cordectomy. There was variability amongst the type of cordectomy performed for T1 glottic cancer, including two studies $[23,26]$ that performed type I or II, one study [22] that performed solely type II, one study [18] that performed type III or IV, and one study [12] that performed type IV or V. In terms of RT, most studies [11, 12, 14, 18, 19, 21-28] reported dose and treatment regimens, with the average dose ranging from 60 to $73 \mathrm{~Gy}$. The source of radiation was most often a 6-MV linear accelerator. Some studies used a 4MV or 18-MV linear accelerator [24, 27], x-rays [28], or a Co60 unit $[24,27,28]$.

The majority of studies reported oncologic outcomes for T1a glottic cancer, with five studies [12, 15, 21, 24] reporting outcomes for both $\mathrm{T} 1 \mathrm{a}$ and $\mathrm{T} 1 \mathrm{~b}$, and one study [13] reporting outcomes solely for T1b. Four studies $[15,19,20,24]$ also reported separate outcomes for T2 glottic cancer in both treatment arms that was not included in our meta-analysis. Lastly, two studies [24, 28] had additional partial laryngectomy treatment arm that was also not included in our analysis. The majority of follow-up time points for reported oncologic outcomes was 5 years. Two studies $[20,25]$ reported oncologic outcomes at 3 years, and three $[13,15,22]$ reported outcomes at 2 years.

\section{Methodological quality}

A methodological quality assessment of eligible studies was performed using a grading tool published by Oxford Centre for Evidence-based Medicine [30] as per previously published methods in the field of otolaryngology $[6,31]$. Additional factors were considered, including the transparency, clarity, and extent of outcome data reported, the inclusion of relevant patient baseline characteristics, clearly defined methods in staging and treatment, and presence of selection bias. There were no 
eligible RCTs or randomized studies for inclusion. Thus, the body of evidence in this systematic review is comprised entirely of non-randomized observational cohort studies, fourteen retrospective and two [13, 25] prospective in design. As a result, the majority of eligible studies were graded as Level III evidence, while 2 studies $[11,25]$ were graded as Level II. Eight of sixteen studies reported potential sources of selection bias, including age of patient $[12,24]$, anterior commissure (AC) involvement [12, 21, 23, 24], tumor characteristics [12, 19, 22], variable treatment time periods $[20,25,26]$, and TNM stage $[19,24]$.

\section{Statistical analysis}

Event numbers of oncologic outcomes from both TLM and RT treatment arms were pooled from eligible studies. Meta-analysis was performed using RevMan 5.3, an open-source statistical analysis software (The Cochrane Collaboration, Oxford, UK). Heterogeneity between studies was assessed via a chi-square analysis and the I [2] test, with significance set at $P<0.1$. Included studies are considered to have low heterogeneity (or be homogeneous) if I [2] is less than $25 \%$, moderate heterogeneity if I [2] is 25 to $50 \%$, and high heterogeneity if I [2] is greater than $50 \%$. If homogeneity existed between studies, meta-analysis was performed with a fixed effect model. If significant heterogeneity was confirmed, either by significant chi-square test $(P<0.1)$ or I [2] greater than $50 \%$, meta-analysis was performed using a random effects model. Lastly, a pooled odds ratio (OR) was performed with 95\% confidence interval (CI), and the overall effect was assessed via the $z$ statistic with statistical significance set at $P<0.05$.

\section{Results}

\section{Oncologic outcomes}

Oncologic outcomes for included studies are reported as number of events with sample size for reference in Table 2. All 16 eligible studies were included in at least one oncologic outcome meta-analysis. The majority of studies reported laryngeal preservation and local control as primary outcomes.

\section{Overall survival}

Of the sixteen studies included in our meta-analysis, ten $[11-15,19,22,23,25,26]$ reported overall survival event numbers for both TLM and RT treatment arms (Fig. 2). The total patient population was 685 in the TLM arm and 608 in the RT arm. One study [22] reported $100 \%$ overall survival in both the TLM and RT treatment arms and thus could not be included in the analysis. Metaanalysis revealed low heterogeneity among the eight retrospective and two prospective cohort studies $\left(\mathrm{Chi}^{2}=\right.$ 2.20, $P=0.97, \mathrm{I}^{2}=0 \%$ ), and the fixed effect model was applied. The pooled analysis significantly favoured TLM for overall survival of $\mathrm{T} 1$ glottic cancer patients, with an OR of $1.52(95 \%$ CI of $1.07,2.14)$ and a $\mathrm{Z}$ score of 2.36 $(P=0.02)$.

\section{Disease-specific survival}

Twelve of sixteen studies [11-14, 19-23, 25, 26, 28] reported event numbers for disease specific survival for both TLM and RT treatment arms (Fig. 3). There were 722 patients in the TLM arm and 744 in the RT arm. Two studies $[20,22]$ reported $100 \%$ disease-specific survival in both the TLM and RT treatment arms and were not included in the analysis. There was low heterogeneity among the ten retrospective and two prospective cohort studies $\left(\mathrm{Chi}^{2}=5.13, P=0.82, \mathrm{I}^{2}=0 \%\right)$, and the fixed effect model was applied. Meta-analysis significantly favoured TLM for disease-specific survival in T1 glottic cancer, with an OR of 2.70 (95\% CI of 1.32, 5.54) and a $\mathrm{Z}$ score of $2.71(P=0.007)$.

\section{Laryngeal preservation}

Fifteen of sixteen studies $[11-15,18-23,25-28]$ reported event numbers for laryngeal preservation for both TLM and RT treatment arms (Fig. 4). There were 986 patients in the TLM arm and 929 in the RT arm. There was low heterogeneity among the thirteen retrospective and two prospective cohort studies $\left(\mathrm{Chi}^{2}=11.22, P=\right.$

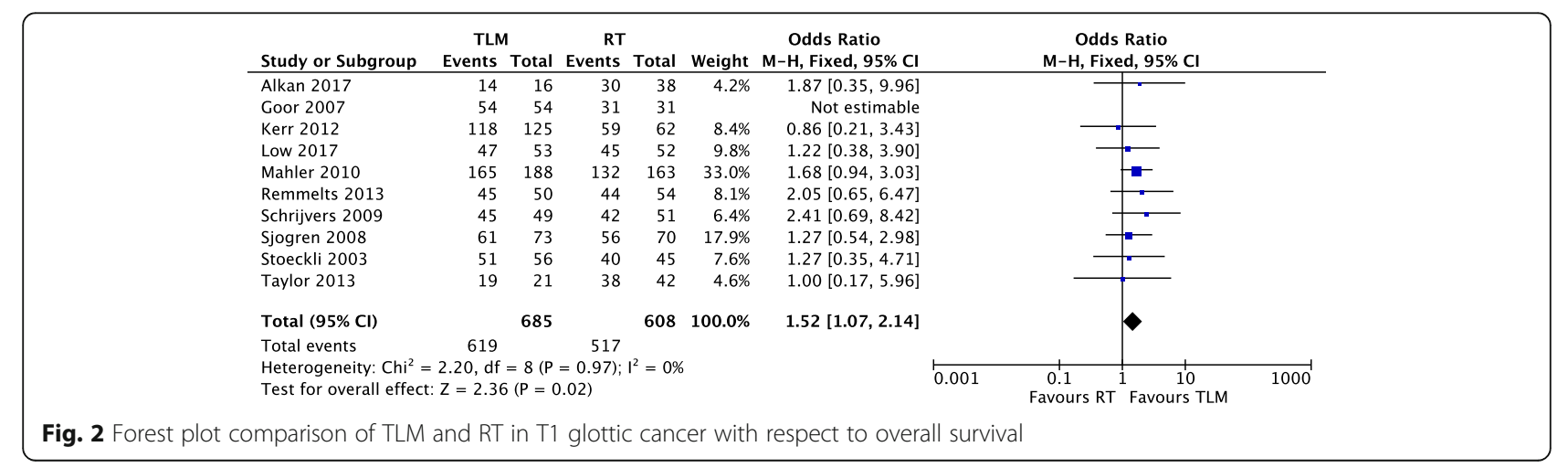




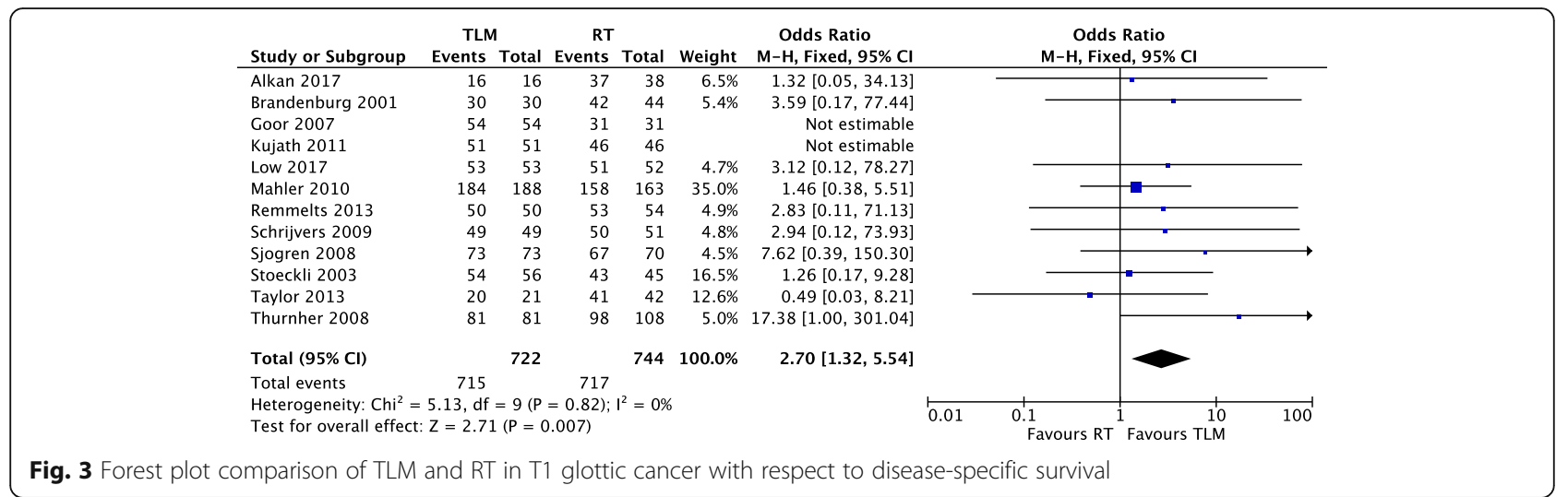

$0.67, \mathrm{I}^{2}=0 \%$, and the fixed effect model was applied. Meta-analysis significantly favoured laryngeal preservation with TLM, with an OR of 6.31 (95\% CI of 3.77, $10.56)$ and a $\mathrm{Z}$ score of $7.00(P<0.00001)$.

\section{Local control}

Fourteen of sixteen studies [11-15, 18-23, 25-28] reported local control event numbers for both TLM and RT treatment arms (Fig. 5). There were 841 patients in the TLM arm and 862 in the RT arm. There was significant heterogeneity among the twelve retrospective and two prospective cohort studies $\left(\mathrm{Chi}^{2}=22.76, P=0.04\right.$, $\left.\mathrm{I}^{2}=43 \%\right)$, and the random effects model was applied. Meta-analysis demonstrated no difference in local control with TLM or RT as primary therapy, with an OR of $1.19(95 \% \mathrm{CI}$ of $0.79,1.81)$ and a Z score of $0.84(P=$ $0.40)$.

\section{Discussion}

Since TLM was introduced in 1972 [2], it has become a preferred therapeutic modality for early glottic cancer. Due to a paucity in high quality research, currently there are equivalently acceptable tools in our armamentarium, including RT. The lack of randomized prospective studies directly comparing TLM and RT has complicated clinical decision making, forcing surgeons to rely upon non-randomized studies. To contribute to improved clinical decision making, we conducted a current and thorough systematic review and meta-analysis of published literature in major electronic databases that assessed oncologic outcomes of T1 glottic cancer patients treated with TLM or RT.

\section{Oncologic outcomes}

Meta-analysis revealed the absence of heterogeneity in all oncologic outcomes with the exception of local control. This was mitigated by the use of a random effects model rather than a fixed effects model in our meta-analysis. To our knowledge we are the first systematic review comparing TLM and RT in early glottic cancer to demonstrate a significant improvement in disease-specific survival with TLM (Fig. 3). In addition, our study shows that TLM is strongly favourable for organ preservation, with an OR of 6.31 for laryngeal preservation in TLM versus RT (Fig. 4). With TLM, patients are therefore approximately six times more likely to preserve their larynx than those treated with RT. This finding is in agreement with three previous systematic reviews

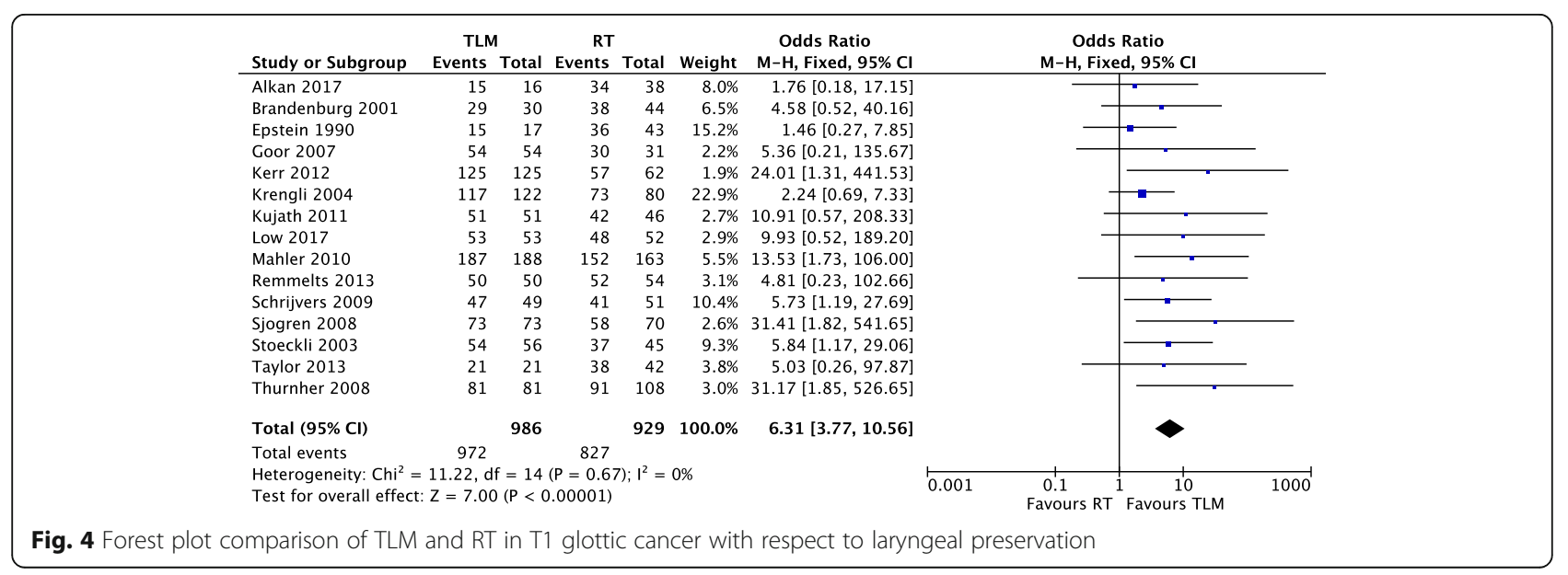




\begin{tabular}{|c|c|c|c|c|c|c|c|c|c|c|c|}
\hline & \multirow{2}{*}{$\begin{array}{l}\text { Study or Subgroup } \\
\text { Alkan } 2017\end{array}$} & TLM & ${ }_{\text {Total }}$ & \multirow{2}{*}{$\begin{array}{r}\text { RT } \\
\text { Events } \\
33\end{array}$} & \multirow{2}{*}{ Total } & \multirow{2}{*}{$\begin{array}{r}\text { Weight } \\
5.5 \%\end{array}$} & \multirow{2}{*}{$\begin{array}{c}\begin{array}{c}\text { Odds Ratio } \\
\text { M-H, Random, } 95 \% \mathrm{Cl}\end{array} \\
0.45[0.10,1.98]\end{array}$} & & \multicolumn{2}{|c|}{\begin{tabular}{c}
\multicolumn{1}{c}{ Odds Ratio } \\
$\mathrm{M}-\mathrm{H}$, Random, $95 \% \mathrm{CI}$
\end{tabular}} & \\
\hline & & 12 & 16 & & & & & & .1 & - & \\
\hline & Brandenburg 2001 & 25 & 30 & 35 & 44 & $7.1 \%$ & $1.29[0.38,4.30]$ & & & . & \\
\hline & Epstein 1990 & 12 & 17 & 37 & 43 & $6.1 \%$ & $0.39[0.10,1.51]$ & & & - & \\
\hline & Goor 2007 & 51 & 54 & 28 & 31 & $4.6 \%$ & $1.82[0.34,9.63]$ & & & & \\
\hline & Krengli 2004 & 117 & 122 & 73 & 80 & $7.2 \%$ & $2.24[0.69,7.33]$ & & & & \\
\hline & Low 2017 & 43 & 53 & 48 & 52 & $6.9 \%$ & $0.36[0.10,1.23]$ & & & $F$ & \\
\hline & Mahler 2010 & 174 & 188 & 145 & 163 & $11.4 \%$ & $1.54[0.74,3.21]$ & & & . & \\
\hline & Remmelts 2013 & 45 & 50 & 51 & 54 & $5.4 \%$ & $0.53[0.12,2.34]$ & & & - & \\
\hline & Rosier 1998 & 26 & 31 & 37 & 41 & $5.8 \%$ & $0.56[0.14,2.30]$ & & & & \\
\hline & Schrijvers 2009 & 36 & 49 & 39 & 51 & $9.6 \%$ & $0.85[0.34,2.11]$ & & & - & \\
\hline & Sjogren 2008 & 65 & 73 & 55 & 70 & $9.3 \%$ & $2.22[0.87,5.62]$ & & & & \\
\hline & Stoeckli 2003 & 49 & 56 & 37 & 45 & $7.9 \%$ & $1.51[0.50,4.55]$ & & - & . & \\
\hline & Taylor 2013 & 20 & 21 & 37 & 42 & $2.9 \%$ & $2.70[0.30,24.76]$ & & & & \\
\hline & Thurnher 2008 & 73 & 81 & 75 & 108 & $10.3 \%$ & $4.01[1.74,9.27]$ & & & $\longrightarrow$ & \\
\hline & Total $(95 \% \mathrm{Cl})$ & & 841 & & 862 & $100.0 \%$ & $1.19[0.79,1.81]$ & & & & \\
\hline & Total events & 748 & & 730 & & & & & & & \\
\hline & $\begin{array}{l}\text { Heterogeneity: } \operatorname{Tau}^{2}= \\
\text { Test for overall effect: }\end{array}$ & $\begin{array}{l}=0.25 ; C h \\
Z=0.84\end{array}$ & $\begin{array}{l}\mathrm{hi}^{2}=22 \\
4(\mathrm{P}=0\end{array}$ & $\begin{array}{l}2.76, d f= \\
.40)\end{array}$ & $=13(\mathrm{P}$ & $=0.04) ; I^{2}$ & $I^{2}=43 \%$ & 0.01 & $\begin{array}{c}0.1 \\
\text { Favours RT }\end{array}$ & \begin{tabular}{|lr} 
& 1 \\
1 & 10 \\
Favours TLM
\end{tabular} & 100 \\
\hline
\end{tabular}

with meta-analyses [5, 6, 32]. In terms of overall survival, debate exists as to whether TLM is advantageous as compared to radiotherapy. Two systematic reviews support this notion $[6,16]$, while two others do not find a significant difference $[5,32]$. With the inclusion of recent studies, we demonstrate that treatment with TLM is associated with improved overall survival over RT in early glottic cancer (Fig. 2). Lastly, we did not demonstrate a significant difference between TLM and RT in local control outcomes of early glottic cancer (Fig. 5). This finding is consistent with multiple systematic reviews published within the last decade [5, 6, 16, 32-34]. Overall, our results confirm that primary therapy with TLM is equally efficacious as RT in local control after an initial resection, but offers an advantage in laryngeal preservation, overall survival, and disease-specific survival. This advantage could arise from the ability to precisely resect lesions and conserve surrounding anatomy with TLM. In this respect, initial TLM does not preclude further use of TLM in the management of local recurrence, and RT remains a viable option. All studies used first recurrence as the endpoint for local control, where many patients can be salvaged by further TLM procedures, and or radiation while preserving the larynx. In comparison, repeat RT for local recurrence is generally not an option and many of these patients are salvaged by a total laryngectomy, contributing to reduced laryngeal preservation.

There were discrepancies between our analysis of oncologic outcomes of TLM versus RT in early glottic cancer and those reported by earlier systematic reviews. As previously highlighted, this may be the result of inclusion of new literature or methodological differences. Thus, if we consider just the recent systematic reviews that analyzed two-armed studies [5, 6, 32], it would appear that TLM has increasingly favourable oncologic outcomes over time. This is consistent with our findings of improved overall survival and disease-specific survival rates in TLM over RT, which is not described in earlier systematic reviews [5, 32]. Our study also had strict inclusion criteria, and thus we excluded some studies from our analysis that were included in earlier systematic reviews. For instance, three earlier reviews $[5,6,32]$ included a study by Spector et al. [35], however, this study did not meet our inclusion criteria as a portion of the TLM cohort received treatment with a KTP laser. Furthermore, our study included reported event numbers for each oncologic outcome, whereas earlier systematic reviews may have extrapolated event numbers from reported Kaplan-Meier percentages. For instance, Mo et al. state that they "converted the percentages into event numbers so as to analyze the combined values of different studies." We did not back-calculate event numbers from actuarial data in this manner to reduce potential error in our analysis. As a result, we excluded a study by Dinapoli et al. [36] and some oncologic outcome data from Rosier et al. [24], that was included in earlier reviews $[5,6]$. Lastly, we excluded any studies that grouped additional stages of glottic cancer into oncologic outcomes. Thus, we excluded a study by Osborn et al. [37] that was included in earlier reviews $[5,6]$ as they combined Tis and T1 patients in the TLM and RT cohorts.

\section{Limitations}

Inherently, the quality of a systematic review is limited by the quality of available literature. There were no available RCTs that met our inclusion criteria. All included studies were observational non-randomized cohort studies, the vast majority retrospective, with two prospective by design. Non-randomization may produce selection bias when allocating patients to treatment cohorts. Nine studies included in our review specified potential sources of selection bias within their methods (Table 1). Most notably, some allocated by tumor characteristics, including favouring RT for stage T1b $[19,24]$, increase tumor depth [22], poor tumor visualization [12, 19], or anterior commissure involvement [12, 21, 23, 24]. Allocating patients to treatment groups by key disease 
characteristics will ultimately create cohorts with significantly different baseline characteristics, and confound results. These studies suggest that the potential selection bias does not create significant differences in cohorts, however, just one [25] reported a statistical analysis of cohort characteristics. Three studies also treated T1 glottic cancer patients with RT years before beginning TLM therapy $[16,21$, 29]. Although unintentional, this can create bias since treatment outcomes are undoubtedly impacted over time by a plethora of factors, including technological advances in health care, surgical skill, and provider experience. In contrast, the remaining seven studies did not report specific selection bias but acknowledged that patient allocation was non-randomized. Authors explained that although patients were counselled on the pros and cons of both therapies, final allocation was ultimately patient preference (Table 1). For example, Stoeckli et al. [19] report that: "advantages of laser surgery, which were explained to the patients, consisted of the single stage and short duration of the definitive treatment, the possibility of histologic examination of the resection margins, and the preservation of radiotherapy for recurrences or future second primary tumors." Evidently, the manner in which treatment options are presented will strongly influence therapy selection and can ultimately introduce selection bias.

Variability was also present in treatment administration. For instance, there was little consensus among reported ELS types of cordectomies, poor reporting on the use of specific cancer staging systems, and just four studies [11, 14, 24, 25] reported parameters used for laser surgery such as power and spot size. There was also some variability in the RT methods, with some studies using a 4-MV or 18-MV linear accelerator [24, 27], x-rays [28], or a Co60 unit [24, 27, 28]. The discrepancies in treatment methods can introduce performance bias, impacting the interpretability of outcomes. Despite this, our meta-analysis revealed little heterogeneity between included studies when assessing oncologic outcomes for overall survival, disease-specific survival, and laryngeal preservation. Therefore, although quality of included studies must be considered, we concluded that TLM has favourable survival outcomes.

The optimal therapy in early glottic cancer will ultimately have superior survival outcomes, functional outcomes, and favourable cost utility. Here we demonstrate that TLM has favourable survival outcomes, however we do not assess functional outcomes or cost utility. A previous randomized trial of 60 men with T1 disease found that RT had favourable voice-outcomes compared to TLM, including less-hoarseness-related inconvenience at 2 years follow-up [38]. In contrast, a meta-analysis published shortly after by $\mathrm{Du}$ et al. [7] suggests that although they did not find significant differences in the Voice Handicap Index (VHI), jitter, or shimmer, TLM had preferable fundamental frequency values over RT. Currently, there is uncertainty as to which treatment modality has favourable functional outcomes given the paucity of research investigating this question. In terms of cost effectiveness, a recent study by Prettyjohns et al. [39] used a Markov decision model to compare cost utility and quality-adjusted life years (QALYs) of TLM and RT in early glottic cancer. They concluded that TLM was a cost-effective strategy with greater QALYs in T1a laryngeal cancers, however, there was uncertainty in T1b-T2 laryngeal cancers.

Additional research, specifically prospective RCTs will be required to address these uncertainties. Unfortunately, performing an RCT that directly compares TLM and RT may be difficult due to a number of factors, including ethical considerations and inherent institutional bias. Several attempted RCTs investigating TLM vs RT have been abandoned due to poor patient recruitment [8]. If RCTs are not possible, future studies may investigate this question using complex statistical models, such as Monte Carlo simulations, to assess probabilities of oncologic and functional outcomes with either modality.

\section{Conclusions}

Our systematic review and meta-analysis examined studies that directly compared oncologic outcomes in T1 glottic cancer with a primary treatment of TLM or RT. There were no eligible RCTs, and all studies included in our analysis were observational cohort studies, with a level II to level III evidence rating. In addition, there was some variability in treatment methods and non-randomized patient allocation to treatment groups, creating bias. As a result, these results should be interpreted with a degree of caution.

Despite limitations, our findings demonstrated that TLM was associated with favourable outcomes in terms of overall survival, disease-specific survival and laryngeal preservation. There was no difference in associated local control between TLM and RT after the initial TLM procedure. The ability to salvage patients who recur after their initial TLM procedure with repeat TLM or radiation may explain the associated improvement in overall survival, disease specific survival and laryngeal preservation despite the associated equivalence in initial local control.

Overall, our analysis has contributed to improving our understanding of optimal management in early glottic cancer. Determining optimal therapeutic management in glottic cancer must also consider the availability of the therapy, patient preference, cost utility, and inherent advantages of each modality. Ultimately, well-designed prospective and multicentre RCTs or studies using statistical modelling will be required to provide higher quality evidence in addressing the remaining uncertainties, corroborating the efficacy of TLM in early glottic cancer, and establishing clinical guidelines. 


\section{Abbreviations}

AC: Anterior commissure; AJCC: American Joint Committee on Cancer; Cl: Confidence interval; OR: Odds ratio; QALYs: Quality-adjusted life years; RCT: Randomized-control trial; RT: Radiotherapy; TLM: Transoral laser microsurgery; UICC: Union for International Cancer Control

\section{Acknowledgements}

Not applicable.

\section{Authors contribution}

MFV contributed to the design of the study, acquisition, analysis, and interpretation of the data, and drafting of the manuscript, tables, and figures. CAM contributed to the design of the study, acquisition, analysis, and interpretation of the data, and substantial revision of the manuscript. MHR is the corresponding author and contributed to the design of the study, data analysis and interpretation, and revision of the manuscript. SMT, JRBT, and $\mathrm{RDH}$ contributed to study design and revisions of the manuscript. All authors approved the submitted version of the manuscript and agreed both to be personally accountable for the author's own contributions to the work.

\section{Funding}

Not applicable.

\section{Availability of data and materials}

All data generated or analysed during this study are included in this published article.

\section{Ethics approval and consent to participate}

Not applicable.

\section{Consent for publication}

Not applicable.

\section{Competing interests}

The authors declare that they have no competing interests.

\section{Author details}

'Dalhousie Medical School, Dalhousie University, Halifax, Nova Scotia, Canada. ${ }^{2}$ Dalhousie Division of Otolaryngology - Head and Neck Surgery, Dalhousie University, Suite 3044, Dickson Bldg. 5820 University Avenue, Halifax, NS B3H 1V9, Canada.

\section{Received: 31 May 2019 Accepted: 20 August 2019}

\section{Published online: 03 September 2019}

\section{References}

1. Canadian Cancer Statistics 2017. 2017. Toronto, ON: Canadian Cancer Society.

2. Strong MS, Jako GJ. Laser surgery in the larynx. Early clinical experience with continuous CO 2 laser. Ann Otol Rhinol Laryngol. 1972;81:791-8 1972/12/01.

3. Steiner $W$. Experience in endoscopic laser surgery of malignant tumours of the upper aero-digestive tract. Adv Otorhinolaryngol. 1988;39:135-44 1988/01/01.

4. Silver CE, Beitler JJ, Shaha AR, et al. Current trends in initial management of laryngeal cancer: the declining use of open surgery. Eur Arch Otorhinolaryngol. 2009;266:1333-52. 2009/07/15. https://doi.org/10.1007/ s00405-009-1028-2.

5. Yoo J, Lacchetti C, Hammond JA, et al. Role of endolaryngeal surgery (with or without laser) versus radiotherapy in the management of early ( $\mathrm{T} 1)$ glottic cancer: a systematic review. Head Neck. 2014;36:1807-19. 2013/10/ 12. https://doi.org/10.1002/hed.23504.

6. Mo HL, Li J, Yang X, et al. Transoral laser microsurgery versus radiotherapy for T1 glottic carcinoma: a systematic review and meta-analysis. Lasers Med Sci. 2017:32:461-7. 2016/12/15. https://doi.org/10.1007/s10103-016-2103-8.

7. Du G, Liu C, Yu W, et al. Voice outcomes after laser surgery vs. radiotherapy of early glottic carcinoma: a meta-analysis. Int J Clin Exp Med. 2015;8:17206-13.

8. Warner L, Chudasama J, Kelly CG, et al. Radiotherapy versus open surgery versus endolaryngeal surgery (with or without laser) for early laryngeal squamous cell cancer. The Cochrane database of systematic reviews. 2014 Cd002027. 2014/12/17. https://doi.org/10.1002/14651858.CD002027.pub2.
9. Makki FM, Williams B, Rajaraman M, et al. Current practice patterns in the management of glottic cancer in Canada: results of a national survey. J Otolaryngol Head Neck Surg. 2011;40:205-10. 2011/04/27.

10. O'Sullivan B, Mackillop W, Gilbert R, et al. Controversies in the management of laryngeal cancer: results of an international survey of patterns of care. Radiother Oncol. 1994;31:23-32. 1994/04/01.

11. Low TH, Yeh D, Zhang T, et al. Evaluating organ preservation outcome as treatment endpoint for T1aN0 glottic cancer. Laryngoscope. 2017;127:1322 -7. 2016/10/26. https://doi.org/10.1002/lary.26317.

12. Alkan $U$, Nachalon $Y$, Shkedy $Y$, et al. $T 1$ squamous cell carcinoma of the glottis with anterior commissure involvement: Radiotherapy versus transoral laser microsurgery. Head Neck. 2017;39:1101-5. 2017/04/04. https://doi.org/1 $0.1002 /$ hed.24723.

13. Taylor SM, Kerr P, Fung K, et al. Treatment of T1b glottic SCC: laser vs. Radiationa Canadian multicenter study. J Otolaryngol Head Neck Surg. 2013; 42. https://doi.org/10.1186/1916-0216-42-22.

14. Remmelts AJ, Hoebers FJP, Klop WMC, et al. Evaluation of lasersurgery and radiotherapy as treatment modalities in early stage laryngeal carcinoma: tumour outcome and quality of voice. Eur Arch Otorhinolaryngol. 2013;270: 2079-87. https://doi.org/10.1007/s00405-013-2460-x.

15. Kerr $\mathrm{P}$, Mark Taylor S, Rigby M, et al. Oncologic and voice outcomes after treatment of early glottic cancer: transoral laser microsurgery versus radiotherapy. J Otolaryngol Head Neck Surg. 2012;41:381-8 2013/05/24.

16. Higgins KM, Shah MD, Ogaick MJ, et al. Treatment of early-stage glottic cancer: meta-analysis comparison of laser excision versus radiotherapy. J Otolaryngol Head Neck Surg. 2009;38:603-12 2009/12/05.

17. Kwon $Y$, Lemieux M, McTavish J, et al. Identifying and removing duplicate records from systematic review searches. J Med Libr Assoc. 2015;103:184 -188. 2015/10/30. https://doi.org/10.3163/1536-5050.103.4.004.

18. Krengli M, Policarpo M, Manfredda I, et al. Voice quality after treatment for T1a glottic carcinoma--radiotherapy versus laser cordectomy. Acta Oncol (Stockholm, Sweden). 2004:43:284-9 2004/07/13.

19. Stoeckli SJ, Schnieper I, Huguenin P, et al. Early glottic carcinoma: treatment according patient's preference? Head Neck. 2003;25:1051-6. 2003/12/04 https://doi.org/10.1002/hed.10323.

20. Kujath $M$, Kerr P, Myers $C$, et al. Functional outcomes and laryngectomy-free survival after transoral $\mathrm{CO}(2)$ laser microsurgery for stage 1 and 2 glottic carcinoma. J Otolaryngol Head Neck Surg. 2011; 40(Suppl 1):S49-58. 2011/04/06.

21. Brandenburg JH. Laser cordotomy versus radiotherapy: an objective cost analysis. Ann Otol Rhinol Laryngol. 2001;110:312-8. 2001/04/20. https://doi. org/10.1177/000348940111000404.

22. Goor KM, Peeters AJ, Mahieu HF, et al. Cordectomy by CO2 laser or radiotherapy for small T1a glottic carcinomas: costs, local control, survival, quality of life, and voice quality. Head Neck. 2007;29:128-36. 2006/11/24. https://doi.org/10.1002/hed.20500.

23. Sjogren EV, Langeveld TP, Baatenburg de Jong RJ. Clinical outcome of T1 glottic carcinoma since the introduction of endoscopic CO2 laser surgery as treatment option. Head Neck. 2008;30:1167-74. 2008/06/06. https://doi. org/10.1002/hed.20852.

24. Rosier JF, Gregoire V, Counoy H, et al. Comparison of external radiotherapy, laser microsurgery and partial laryngectomy for the treatment of T1N0M0 glottic carcinomas: a retrospective evaluation. Radiother Oncol. 1998;48:175-83 1998/10/23.

25. Mahler $\mathrm{V}$, Boysen $\mathrm{M}$, Brondbo K. Radiotherapy or $\mathrm{CO}(2)$ laser surgery as treatment of T(1a) glottic carcinoma? Eur Arch Otorhinolaryngol. 2010;267: 743-50. 2009/11/10. https://doi.org/10.1007/s00405-009-1135-0.

26. Schrijvers ML, van Riel EL, Langendijk JA, et al. Higher laryngeal preservation rate after $\mathrm{CO} 2$ laser surgery compared with radiotherapy in T1a glottic laryngeal carcinoma. Head Neck. 2009;31:759-64. 2009/03/05. https://doi. org/10.1002/hed.21027.

27. Epstein BE, Lee DJ, Kashima $\mathrm{H}$, et al. Stage $\mathrm{T1}$ glottic carcinoma: results of radiation therapy or laser excision. Radiology. 1990;175:567-70. 1990/05/01. https://doi.org/10.1148/radiology.175.2.2326483.

28. Thurnher D, Erovic BM, Frommlet F, et al. Challenging a dogma--surgery yields superior long-term results for T1a squamous cell carcinoma of the glottic larynx compared to radiotherapy. Eur J Surg Oncol. 2008;34:692-8. 2007/08/10. https://doi.org/10.1016/j.ejso.2007.06.008.

29. Remacle M, Eckel HE, Antonelli A, et al. Endoscopic cordectomy. A proposal for a classification by the working committee, European laryngological society. Eur Arch Otorhinolaryngol. 2000;257:227-31 2000/06/27. 
30. Howick J, Chalmers I, Glasziou P, et al. The Oxford 2011 Levels of Evidence, http://www.cebm.net/index.aspx?o=5653 (2011, accessed 23 Aug 2018)

31. Wasserman JM, Wynn R, Bash TS, et al. Levels of evidence in otolaryngology journals. Otolaryngol Head Neck Surg. 2006;134:717-23. 2006/05/02. https:// doi.org/10.1016/j.otohns.2005.11.049.

32. Abdurehim Y, Hua Z, Yasin Y, et al. Transoral laser surgery versus radiotherapy: systematic review and meta-analysis for treatment options of T1a glottic cancer. Head Neck. 2012;34:23-33. 2011/03/05. https://doi.org/1 0.1002/hed.21686.

33. O'Hara J, Markey A, Homer JJ. Transoral laser surgery versus radiotherapy for tumour stage 1a or $1 \mathrm{~b}$ glottic squamous cell carcinoma: systematic review of local control outcomes. J Laryngol Otol. 2013;127:732-8. 2013/07/10. https://doi.org/10.1017/s0022215113001400.

34. Feng $Y$, Wang $B$, Wen $S$. Laser surgery versus radiotherapy for T1-T2NO glottic cancer: a meta-analysis. ORL J Otorhinolaryngol Relat Spec. 2011;73. 336-42. 2011/10/19. https://doi.org/10.1159/000327097.

35. Spector JG, Sessions DG, Chao KS, et al. Stage I (T1 NO MO) squamous cell carcinoma of the laryngeal glottis: therapeutic results and voice preservation. Head Neck. 1999;21:707-17 1999/11/24.

36. Dinapoli N, Parrilla C, Galli J, et al. Multidisciplinary approach in the treatment of $\mathrm{T} 1 \mathrm{glottic}$ cancer. The role of patient preference in a homogenous patient population. Strahlenther Onkol. 2010;186:607-13. 2010/11/12. https://doi.org/10.1007/s00066-010-2142-1.

37. Osborn HA, Hu A, Venkatesan V, et al. Comparison of endoscopic laser resection versus radiation therapy for the treatment of early glottic carcinoma. J Otolaryngol Head Neck Surg. 2011:40:200-4. 2011/04/27.

38. Aaltonen LM, Rautiainen N, Sellman J, et al. Voice quality after treatment of early vocal cord cancer: a randomized trial comparing laser surgery with radiation therapy. Int J Radiat Oncol Biol Phys. 2014;90:255-60. https://doi. org/10.1016/j.jjrobp.2014.06.032.

39. Prettyjohns $\mathrm{M}$, Winter $\mathrm{S}$, Kerawala $\mathrm{C}$, et al. Transoral laser microsurgery versus radiation therapy in the management of $\mathrm{T} 1$ and $\mathrm{T} 2$ laryngeal glottic carcinoma: which modality is cost-effective within the UK? Clin Otolaryngol. 2017;42:404-15. 2016/12/15. https://doi.org/10.1111/coa.12807.

\section{Publisher's Note}

Springer Nature remains neutral with regard to jurisdictional claims in published maps and institutional affiliations.

Ready to submit your research? Choose BMC and benefit from:

- fast, convenient online submission

- thorough peer review by experienced researchers in your field

- rapid publication on acceptance

- support for research data, including large and complex data types

- gold Open Access which fosters wider collaboration and increased citations

- maximum visibility for your research: over $100 \mathrm{M}$ website views per year

At $\mathrm{BMC}$, research is always in progress.

Learn more biomedcentral.com/submissions 